The projected donor rates for New South Wales calculated by two different methods are contained in table VI. The differences in the rates are due to differences in the sizes of the potential donor poolthat is, the realistic medically suitable potential donor rate. If it is assumed that the realistic medically suitable potential donor rate for New South Wales is the same as that in the study hospitals then the actual donor rate would be as high as $18 /$ million population/year. On the other hand, the pool of potential donors implied by the actual donor rate (assuming the same conversion rate as observed in the study hospitals) is smaller than that projected in the first method $(51 / \mathrm{million}$ population/year $v 76 /$ million population/year). It is derived from an actual donor rate of 13/million population/year. The same explanation applies to differences in rates for missed potential donors and potential donors with permission refused for the two methods of projection. It is important to note, however, that even if the donor rate is $13 /$ million population/year there is opportunity to increase it by converting missed potential donors to actual donors (an increase of nine donors/million population/year) and by overcoming refusal of permission (an increase of 13 donors/million population/year). If both are overcome the projected rate would be $45 /$ million population/ year. Neither calculation of donor rates takes into account the possibility of potential donors created by interventional ventilation-that is, unrealistic potential donors in whom resuscitation would be solely for the purpose of organ retrieval.

It has been calculated that to satisfy the demand for cadaveric renal transplantation in New South Wales in 1990 and to catch up with the backlog over five years the supply rate needs to be increased $117 \%$; the actual donor rate needs to be increased by $15 /$ million population/year.' Assuming current community attitudes towards retrieval and our low projection of the potential for cadaveric retrieval, conversion of missed potential donors to actual donors would increase supply by about $70 \%(9 / 13$, table VI). If our high projection of the potential for cadaveric retrieval is assumed then the increase would be about $80 \%(15 / 18$, table VI).

In conclusion, this study has shown that there is significant unused potential for cadaveric organ retrieval in New South Wales. The two major obstacles are reluctance on the part of medical practitioners to resuscitate potential donors and refusal of permission by the next of kin. This study creates hope that by overcoming these two obstacles, cadaveric organ supply can be increased sufficiently to satisfy demand for all types of organ transplantation. It will be important to find out whether the first obstacle can be overcome by educational intervention among health care providers, and for this the second phase of this study is now in progress.

This work was supported by grants from the New South Wales Department of Health and Sandoz (Australia)

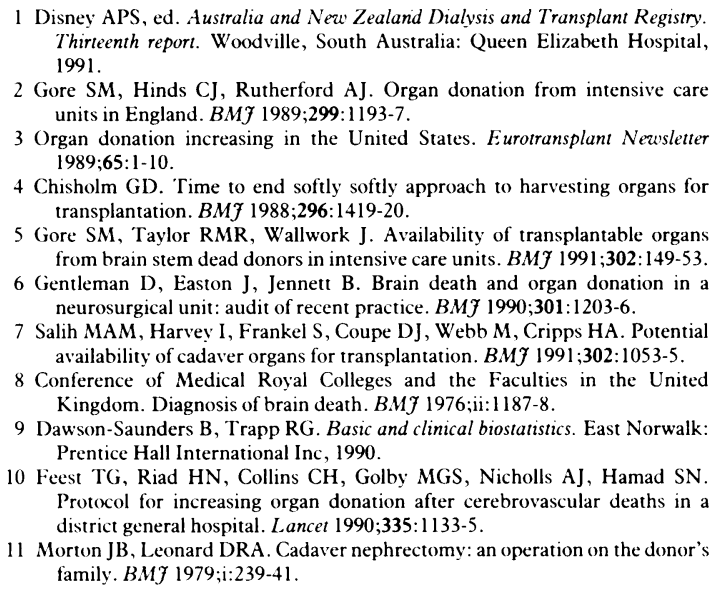

10 Feest TG, Riad HN, Collins CH, Golby MGS, Nicholls AJ, Hamad SN Protocol for increasing organ donation after cerebrovascular deaths in a district general hospital. Lancet 1990;335:1133-5.

11 Morton JB, Leonard DRA. Cadaver nephrectomy: an operation on the donor's family. BMF 1979;i:239-41.

Institute of Cancer

Research and Royal

Marsden Hospital, Sutton,

Surrey SM2 5PT

M Brada, senior lecturer and consultant in radiotherapy and oncology, neuro-oncology unit and academic unit of radiotherapy and oncology

D Ford, statistician, section of epidemiology

$S$ Ashley, computer analyst

J M Bliss, statistician, section of epidemiology

S Crowley, research assistant, neuro-oncology unit

M Mason, lecturer in radiotherapy and oncology, neuro-oncology unit B Rajan, visiting research fellow, neuro-oncology unit D Traish, research assistant, neuro-oncology unit

Correspondence to:

Dr Brada.

BMF 1992;304: 13+3-6

\title{
Risk of second brain tumour after conservative surgery and radiotherapy for pituitary adenoma
}

\author{
M Brada, D Ford, S Ashley, J M Bliss, S Crowley, M Mason, B Rajan, D Traish
}

\section{Abstract}

Objective-To assess the risk of second brain tumour in patients with pituitary adenoma treated with conservative surgery and external beam radiotherapy.

Design-Long term follow up of a cohort of patients with pituitary adenoma and comparison of tumour occurrence with population incidence rates.

Setting-The Royal Marsden Hospital.

Subjects -334 patients with pituitary adenoma treated with conservative surgery and radiotherapy (median dose $45 \mathrm{~Gy}$ ) and followed up for 3760 person years.

Main outcome measures-Second intracranial tumour and systemic malignancy.

Results-Five patients developed a second brain tumour: two had astrocytoma, two meningioma, and one meningeal sarcoma. The cumulative risk of developing a second brain tumour over the first $\mathbf{1 0}$ years after treatment was $1 \cdot 3 \%(95 \%$ confidence interval $0.4 \%$ to $3.9 \%)$ and over 20 years $1.9 \%(0.7 \%$ to $5.0 \%)$. The relative risk of a second brain tumour compared with the incidence in the normal population was 9.38 (3.05 to 21.89). There was no excess risk of any other type of second primary malignancy.

Conclusions - There is an increased risk of second intracranial tumour in patients with pituitary adenoma treated with surgery and radiotherapy. Although radiation is likely to be the most important factor contributing to the excess risk, further study is required in a cohort of similar patients not receiving radiation.

\section{Introduction}

Pituitary adenomas are successfully treated with a range of treatment modalities, which include surgery, radiotherapy, and medical treatment. ${ }^{1.7}$ Radiotherapy is principally employed to reduce the recurrence rate of incompletely excised non-secreting adenomas and in secreting pituitary tumours where hormonal control cannot be achieved with surgery and medical therapy. In these situations radiotherapy combined with limited surgery is successful in controlling pituitary adenoma, resulting in a $90 \% 10$ year progression free survival. ${ }^{134}$ Radiotherapy is relatively safe, with less than $1 \%$ 
incidence of optic nerve and chiasmal damage, provided that it is delivered accurately and follows well established principles of radiation tolerance. ${ }^{8910}$

Radiation has been implicated in the causation of brain tumours, ${ }^{11}$ and many individual cases of a second brain tumour have been reported after treatment of pituitary adenoma and other brain lesions. However, the risk to an individual of developing a second tumour either of the central nervous system or at peripheral sites is not known. We have followed a cohort of patients with pituitary adenoma treated with limited surgery and radiotherapy and report the incidence of second tumours by site and the relative risk compared with tumour incidence in the normal population. This information defines the risk for individual patients and should provide a basis for comparison with other treatment approaches.

\section{Patients and methods}

The cohort under study consisted of 436 patients with pituitary adenoma who received radiotherapy at the Royal Marsden Hospital between 1962 and 1986 after surgery at the Atkinson Morley's Hospital, the National Hospital, and other referring neurosurgical hospitals. The diagnosis of pituitary adenoma was either confirmed histologically or based on clinical and radiological features and endocrine abnormalities. The median dose of radiotherapy was 45 Gy in 25-30 fractions, and treatment was delivered by using a three

TABLE I-Characteristics of patients with pituitary adenoma. Except where stated otherwise figures are numbers of patients

\begin{tabular}{lc}
\hline & $\begin{array}{c}\text { Patients with } \\
\text { pituitary adenoma }\end{array}$ \\
\hline Total in series & 334 \\
Median age (years) (range) & $49(15-78)$ \\
Primary referral & 319 \\
Referral at recurrence & 15 \\
Tumour type: & \\
Hormone secreting & 104 \\
Non-secreting & 210 \\
Unknown & 20 \\
Histological confirmation & 260 \\
Radiation dose (Gy): & \\
<40 & 7 \\
40-44 & 104 \\
45-49 & 746 \\
₹50 & 77 \\
Radiotherapy apparatus: & 331 \\
Linear accelerator & 3 \\
Cobalt & \\
Extent of surgery: & 8 \\
Complete & 245 \\
Incomplete & 68 \\
Biopsy/no surgery & 13 \\
Not known & \\
Medical treatment: & 53 \\
Bromocriptine & 281 \\
No bromocriptine & 3760 \\
Years of follow up & \\
&
\end{tabular}

TABLE II - Details of five patients with pituitary adenoma who developed second intracranial tumours

\begin{tabular}{cccccc}
\hline $\begin{array}{c}\text { Case } \\
\text { No }\end{array}$ & $\begin{array}{c}\text { Age at diagnosis of } \\
\text { pituitary adenoma } \\
\text { (years) }\end{array}$ & Sex & $\begin{array}{c}\text { Years since } \\
\text { radiotherapy }\end{array}$ & Second tumour & \multicolumn{1}{c}{ Site } \\
\hline 1 & 54 & $M$ & 6 & Astrocytoma (Kernohan grade IV) & Left frontal \\
2 & 40 & F & 7 & Astrocytoma (Kernohan grade IV) & Right temporal \\
3 & 48 & F & 7 & Meningeal sarcoma & Sella \\
4 & 19 & F & 10 & Meningioma & Right sphenoidal \\
5 & 58 & F & 21 & Meningioma & \\
\hline
\end{tabular}

TABLE III - Incidence and relative risk of second intracranial tumours (334 patients; 3760 person years)

\begin{tabular}{|c|c|c|c|c|}
\hline Tumour & $\begin{array}{l}\text { No of } \\
\text { second tumours } \\
\text { observed }\end{array}$ & $\begin{array}{l}\text { No of } \\
\text { second tumours } \\
\text { expected }\end{array}$ & $\begin{array}{c}\text { Relative risk } \\
(95 \% \text { confidence interval })\end{array}$ & $\begin{array}{l}\text { Two sided } \\
\text { p value }\end{array}$ \\
\hline Astrocytoma & 2 & 0.25 & $7.92(0.96$ to 28.61$)$ & $0 \cdot 06$ \\
\hline Meningeal tumour & 3 & 0.08 & $37.33(7.69$ to 109.08$)$ & $<0.001$ \\
\hline All & 5 & 0.53 & $9.38(3.05$ to 21.89$)$ & $<0.001$ \\
\hline
\end{tabular}

TABLE IV - Incidence and relative risk of second intracranial tumours

\begin{tabular}{|c|c|c|c|c|c|}
\hline $\begin{array}{l}\text { Years since } \\
\text { radiotherapy }\end{array}$ & $\begin{array}{l}\text { No in } \\
\text { group }\end{array}$ & $\begin{array}{c}\text { No of } \\
\text { person years }\end{array}$ & $\begin{array}{l}\text { No of second } \\
\text { tumours } \\
\text { observed }\end{array}$ & $\begin{array}{l}\text { No of second } \\
\text { tumours } \\
\text { expected }\end{array}$ & $\begin{array}{c}\text { Relative } \\
\text { risk }\end{array}$ \\
\hline $0-4$ & 334 & $1493 \cdot 35$ & 0 & $0 \cdot 18$ & 0 \\
\hline $5-9$ & 261 & $1088 \cdot 78$ & 3 & 0.15 & $20 \cdot 01$ \\
\hline $10-19$ & 173 & $1029 \cdot 71$ & 1 & $0 \cdot 17$ & $5 \cdot 80$ \\
\hline $20-29$ & 49 & $148 \cdot 54$ & 1 & 0.03 & $34 \cdot 26$ \\
\hline Total & 334 & $3760 \cdot 37$ & 5 & 0.53 & $9 \cdot 38$ \\
\hline
\end{tabular}

field technique with an anterior oblique and two lateral fields.

Patients were followed up at the Royal Marsden Hospital or in an endocrine clinic attended by a neurooncologist. Patients who had last been seen more than one year before the date of analysis were traced through a postal questionnaire addressed to the general practitioner and referring hospital. In addition, the cohort was flagged for second tumours through the Thames Cancer Registry.

Of the 436 patients, 102 were resident overseas and were excluded from analysis. Their follow up was poor and they contributed only 427 of the total 4187 person years. The absence of second tumours at any site in that group of patients, who constituted almost a quarter of the cohort, also suggested that their data may be incomplete. The characteristics of the remaining 334 patients, who are the subject of this study, are shown in table I.

Statistical methods - The date of entry into the cohort was taken to be the date of start of radiotherapy at the Royal Marsden Hospital. The risk to patients of a second brain tumour after commencement of radiotherapy was estimated by the Kaplan-Meier survival method..$^{12}$ The computer program Person-Years ${ }^{13}$ was used to compute and compare observed and expected numbers of second malignancies. Expected numbers were calculated from the observed number of person years at risk and population based incidence rates broken down by sex and five year intervals of age and calendar period. Patients were censored on reaching age 85 since tumour incidence rates for the very elderly may be unreliable. ${ }^{14}$ Expected numbers of brain tumours, in total and by specific tumour type, were computed by using incidence rates in the South Thames region (available from the Thames Cancer Registry for 1961-88). Expected numbers of other second tumours were computed by using incidence rates for England and Wales (supplied by the Office of Population Censuses and Surveys; data available for 1971-84). In all analyses patients who had had a second tumour of a different type from the one under consideration were censored at the date of that tumour. All calculated $\mathrm{p}$ values are two sided and based on the Poisson distribution. The $95 \%$ confidence intervals for relative risk (observed to expected ratio) are exact. ${ }^{\text {is }}$

\section{Results}

Five of the 334 patients with pituitary adenoma treated with conservative surgery and radiotherapy developed a second intracranial tumour (table II). Two patients had astrocytoma, two a meningioma, and one a meningeal sarcoma. The diagnosis of second brain tumour was confirmed histologically in four patients (cases 1-4). In case 5 meningioma was diagnosed by computed tomography three days before death (fig 1). Postmortem examination was not carried out. As far as could be determined the sites of tumour were within the region of entry of anterior or lateral radiation fields, and one tumour arose from within the pituitary fossa (table II).

The cumulative risk of second brain tumour over the first 10 years after radiotherapy was $1 \cdot 3 \%$ ( $95 \%$ 
confidence interval $0 \cdot 4 \%$ to $3 \cdot 9 \%$ ) and over 20 years $1.9 \%(0.7 \%$ to $5.0 \%)$ (fig 2$)$. The observed risk of five intracranial tumours per 3760 patient years compared to an expected risk of $0.53(\mathrm{p}<0.001)$. This implied a relative risk to patients of 9.38 ( $95 \%$ confidence interval 3.05 to 21.89 ) compared with the risk of a brain tumour in the general population (table III). The results were analysed by tumour type (table III). Two

TABLE V-Details of 19 patients with pituitary adenoma who developed second tumours outside cranial cavity

\begin{tabular}{ccccl}
\hline $\begin{array}{c}\text { Case } \\
\text { No }\end{array}$ & $\begin{array}{c}\text { Age at diagnosis of } \\
\text { pituitary adenoma } \\
\text { (years) }\end{array}$ & Sex & $\begin{array}{c}\text { Years since } \\
\text { radiotherapy }\end{array}$ & \multicolumn{1}{c}{ Second tumour } \\
\hline 6 & 35 & $\mathrm{~F}$ & $0 \cdot 2$ & Malignant melanoma \\
7 & 79 & $\mathrm{M}$ & $0 \cdot 6$ & Basal cell carcinoma \\
8 & 73 & $\mathrm{M}$ & 1 & Adenocarcinoma colon \\
9 & 52 & $\mathrm{~F}$ & 2 & Breast cancer \\
10 & 62 & $\mathrm{~F}$ & 3 & Basal cell carcinoma \\
11 & 69 & $\mathrm{~F}$ & 4 & Uterine adenocarcinoma \\
$12^{\star}$ & 48 & $\mathrm{M}$ & 6 & Cervical cancer \\
13 & 55 & $\mathrm{~F}$ & 7 & Adenocarcinoma pancreas \\
$14^{\star}$ & 49 & $\mathrm{~F}$ & 8 & Pancreatic cancer \\
$15^{\star}$ & 74 & $\mathrm{M}$ & 10 & Breast cancer \\
$16^{\star}$ & 62 & $\mathrm{~F}$ & 11 & Breast cancer \\
17 & 65 & $\mathrm{M}$ & 13 & Transitional cell bladder carcinoma \\
$18^{\star}$ & 50 & $\mathrm{~F}$ & 13 & Breast cancer \\
19 & 53 & $\mathrm{M}$ & 15 & Bdenocarcinoma caecum \\
$20^{\star}$ & 47 & $\mathrm{M}$ & 17 & Lung cancer \\
$21^{\star}$ & 70 & $\mathrm{M}$ & 21 & Pancreatic cancer \\
$22^{\star}$ & 46 & $\mathrm{M}$ & 23 & Lung cancer \\
$23^{\star}$ & 53 & & Lung cancer \\
$24^{\star}$ & 47 & & & \\
\hline
\end{tabular}

^Identified at death.

TABLE VI-Incidence and relative risk of other second malignancies

\begin{tabular}{lccc}
\hline Second malignancy (ICD 9 codes) & No observed & No expected & Relative risk \\
\hline Lip, oral cavity, and pharynx (140-149) & 0 & $0 \cdot 41$ & 0 \\
Stomach (151) & 0 & $1 \cdot 49$ & 0 \\
Colon and rectum (153-154) & 2 & $2 \cdot 84$ & $0 \cdot 70$ \\
Other digestive organs (150,155-159) & 3 & $1 \cdot 51$ & $1 \cdot 98$ \\
Respiratory and intrathoracic organs (160-165) & 2 & $5 \cdot 69$ & $0 \cdot 35$ \\
Female breast (174) & 5 & $2 \cdot 41$ & $2 \cdot 08$ \\
Female genitourinary organs (179-184) & 2 & $1 \cdot 50$ & $1 \cdot 33$ \\
Male genitourinary organs (185-187) & 0 & $1 \cdot 28$ & 0 \\
Lymphatic and haematopoietic tissue (200-208) & 0 & $1 \cdot 26$ & 0 \\
Other and unspecified sites (170-173, 175, 180-190, 193-199) & 4 & $5 \cdot 78$ & $0 \cdot 69$ \\
\hline Total & 18 & $24 \cdot 17$ & 0.74
\end{tabular}

^A second lung cancer was diagnosed at death in a patient aged 85 (case 21; table V).

All relative risks $p>0 \cdot 05$.

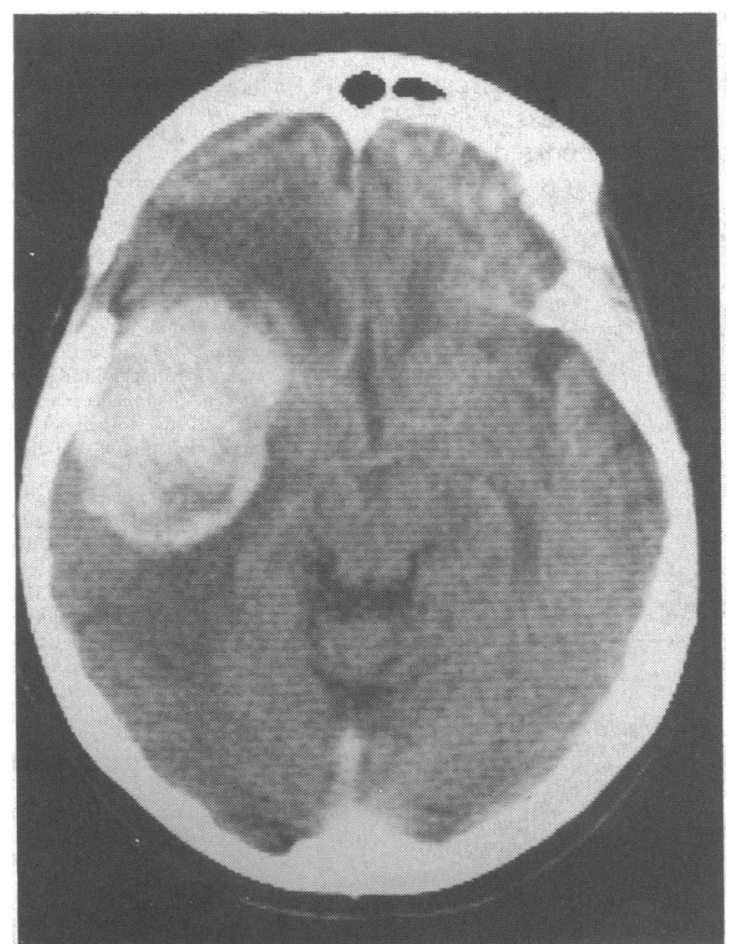

FIG 1-Contrast enhanced computed tomogram in case 5 showing uniformly enhacing right temporal tumour

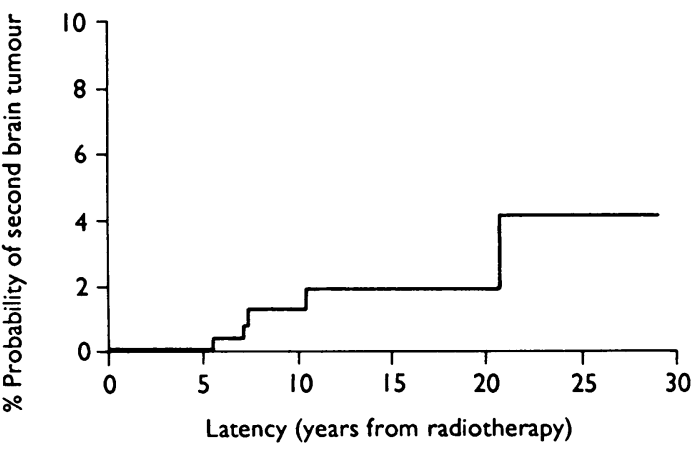

$334 \quad 173 \quad 49 \quad$ Patients at risk FIG 2-Cumulative actuarial risk of second brain tumour in cohort of 334 patients with pituitary adenoma

astrocytomas were observed compared with 0.25 expected $(p=0 \cdot 031)$. Compared with the risk of an astrocytoma in the general population the relative risk to patients was therefore $7.92(95 \%$ confidence interval 0.96 to 28.61 ). Three meningeal tumours were observed compared with 0.08 expected $(p<0.001)$. Compared with the risk of a tumour of the meninges in the general population the relative risk to patients was $37 \cdot 33$ (7.69 to $109 \cdot 08$ ).

There was insufficient information to provide evidence of either an increasing or a decreasing trend in risk by time since radiotherapy (table IV). However, both astrocytomas occurred relatively soon after treatment (six and seven years respectively) whereas meningeal tumours occurred later. None of the five patients had received bromocriptine.

Nineteen patients developed other second tumours at peripheral sites; nine of these were identified at time of death. The details are shown in table $\mathrm{V}$. No evidence of excess risk of second malignancy at non-cranial sites was seen in these patients (table VI). However, it is worth noting that three patients developed pancreatic cancer compared with $0.67 \mathrm{ex}$ pected $(p=0.06)$. When considering mortality from other second tumours no cause specific or overall excess risk was observed. Eleven cancer deaths were observed compared with $15 \cdot 84$ expected $(p=0 \cdot 27)$.

\section{Discussion}

We have found a substantially increased risk of second brain tumours in patients with pituitary adenoma treated with limited surgery and radiotherapy. Many cases of second tumours after treatment of pituitary adenoma, acute lymphatic leukaemia, and other, unrelated brain tumours have been reported, but the number of patients at risk during follow up is not known. The data presented define the overall and relative risks, although small numbers of events have resulted in lack of precision with wide confidence intervals. As a guideline we observed an absolute excess of 4.47 second brain tumours over 3760 patient years, which translates to an excess of 2.4 brain tumours in a group of 100 patients treated in this manner and followed up for 20 years.

As the population under study consisted of patients under close surveillance there was a possibility of bias. We recognise that meningiomas are underreported in the general population since a proportion of tumours are asymptomatic and found only at postmortem examination. It could therefore be argued that the detection of meningiomas in this study was due to close observation. There was, however, no policy of routine scanning, and only symptomatic tumours were recorded. The risk of other malignancies, which was comparable to that expected at national rates, also argues against a serious bias. The high relative risk of second tumours cannot therefore be explained by 
overreporting of cases. Because of the small number of events it is not possible to draw reliable conclusions concerning the effects of possible predisposing factors such as sex, age at the time of treatment, or the secretory status of the tumour.

It is generally assumed that second tumours in the brain are radiation induced. This is based on the recognised increased risk of tumours after low dose irradiation for tinea capitis ${ }^{11}$ and on data from animal experiments. ${ }^{14}$ In addition, there are a number of individual reported cases of second tumour. Gliomas have been reported in leukaemia survivors, ${ }^{16}{ }^{17}$ and this has been postulated to be due to prophylactic cranial irradiation,,$^{18}$ although there is a possible association between central nervous system tumours and haematopoietic malignancy. ${ }^{20}$ In addition to glial tumours, meningiomas and sarcomas have been described after irradiation, ${ }^{1121}$ which may be considered akin to sarcomas developing at other sites after therapeutic radiation. ${ }^{22} 23$

Information concerning family history was not routinely collected for this cohort. It is believed, however, from the information contained in the hospital records of the five patients who developed a second brain tumour that none of the five had a family history of cancer or a genetic syndrome which might increase susceptibility to brain tumours. A familial risk of gliomas is known to exist (D F Easton, personal communication) but there is no evidence of any link with pituitary adenoma. However, the possibility of an association such as a genetic or environmental predisposition between pituitary tumours and second brain tumours which is independent of irradiation cannot be excluded. In order to estimate the risk of a second tumour which can be ascribed to radiation the results should be compared with those in a group of control patients with pituitary tumours treated without radiotherapy. As yet such a series of control patients with long term follow up is not available.

Although it is not possible to define the time course of development of second brain tumours from this study, there is a suggestion that astrocytomas occur earlier and meningiomas later. To examine this in more detail we reviewed all available world literature on cases of second intracranial tumour after treatment of pituitary adenoma and craniopharyngioma. Overall 57 cases of second brain tumour, including five patients from this series, had been reported in 45 publications. There were 12 meningiomas, 24 soft tissue sarcomas, three osteogenic sarcomas, and 18 gliomas. Figure 3 shows the cumulative frequency of reported cases of

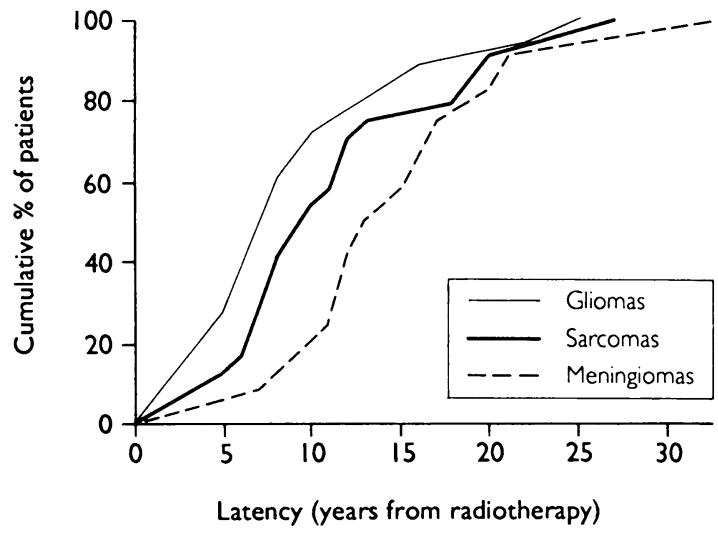

FIG 3-Summary of 54 cases of second brain tumour after treatment of pituitary adenoma and craniopharyngioma from review of case reports published in world literature (18 gliomas, 12 meningiomas, 24 sarcomas, including patients in this study). Cumulative pertcentage of cases plotted against time since radiotherapy second brain tumours. The median time to detection of glioma was $7 \cdot 0$ years (range $1-22$ ), sarcoma $9 \cdot 7$ years (range $5-27$ ), and meningioma $13 \cdot 8$ years (range $7-33$ ).

We conclude that there is an increased risk of second brain tumour in patients with pituitary adenoma treated with surgery and radiotherapy. Second tumours are not conclusively due to radiation, although this is likely to be the most important contributing factor. The data presented should provide a guideline to the risks of therapy in patients with pituitary adenoma, but at present they should not be used as a reason to withhold radiotherapy, which remains an effective treatment modality, particularly in patients with residual or recurrent tumour. For a full comparison of different therapeutic approaches it is necessary to know the risks of all the adverse events after surgery alone, and this would include incidence of second tumours. ${ }^{24}$

The Institute of Cancer Research receives financial support from the Cancer Research Campaign and the Medical Research Council. We also acknowledge support from the Julian Bloom Research Fund and the Royal Marsden Hospital. We thank Karen Linklater and staff of the Thames Cancer Registry for providing information on tumour incidence rates and for flagging this cohort for second malignancies.

1 Halberg FE, Sheline GE. Radiotherapy of pituitary tumors. Pituitary tumors: diagnosis and management. Endocrinol Metab Clin North Am 1987;16: 667-84.

2 Feek CM, McLelland J, Seth J, Toft AD, Irvine WJ, Padfield PL, et al. How effective is external pituitary irradiation for growth hormone-secretin pituitary tumours? Clin Endocrinol 1984;20:401-8.

3 Grigsby PW, Simpson JR, Emami BN, Fineberg BB, Schwartz HG. Prognostic factors and results of surgery and postoperative irradiation in the management of pituitary adenomas. Int $\mathcal{F}$ Radiat Oncol Biol Phys 1989;16: $1411-7$

4 Flickinger JC, Nelson PB, Martinez AJ, Deutsch M, Taylor F. Radiotherapy of nonfunctional adenomas of the pituitary gland. Cancer 1989;63:2409-14.

5 Klibanski A, Zervas NT. Diagnosis and management of hormone-secreting Klibanski A, Zervas NT. Diagnosis and management of

6 Ross DA, Wilson CB. Results of transsphenoidal microsurgery for growth hormone-secreting pituitary adenoma in a series of 214 patients. $f$ Neurosurg 1988:68:854-67.

7 Ebersold MJ, Quast LM, Laws ER, Scheithauer B, Randall RV. Long-term results in transsphenoidal removal of nonfunctioning pituitary tumours. f Neurosurg 1986;64:713-9.

8 Harris JR, Levene MB. Visual complications following irradiation for pituitary adenomas and craniopharyngiomas. Radiology 1976;120:167-71.

9 Aristizabel S, Caldwell WL, Avila J. The relationship of time-dose fractionatio factors to complications in the treatment of pituitary tumours by irradiation. Int $\mathcal{F}$ Radiat Oncol Biol Phys 1977;2:667-73.

10 Dowsett RJ, Fowble B, Sergott R, Savino PJ, Bosley TM, Snyder PJ, et al. Results of radiotherapy in the treatment of acromegaly: lack of ophthalmologic complications. Int f Radiat Oncol Biol Phys 1990;19:453-9.

11 Ron E, Modan B, Boice JD, Alfandary E, Stovall M, Chetrit A, et al. Tumors of the brain and nervous system after radiotherapy in childhood. $N$ Engl $\mathcal{J}$ Med 1988;319:1033-9.

12 Kaplan EL, Meier P. Non-parametric estimation from incomplete observations. Foumal of the American Statistical Association 1978:54:457.

13 Coleman MP, Hermon C, Douglas A. Person-years user manual. Lyons: International Agency for Research on Cancer, 1989.

14 Bernstein M, Laperriere N. Radiation-induced tumors of the nervous system. In: Gutin PH, Leibel SA, Sheline GE, eds. Radiation injury to the nervous system. New York: Raven Press, 1991:480.

15 Breslow NE, Day NE. The design and anlysis of cohort studies. Vol 2. Lyons: International Agency for Research on Cancer, 1987:69.

6 Kingston JE, Hawkins MM, Draper GJ, Marsden HB, Kinnier-Wilson LM Patterns of multiple primary tumours in patients treated for cancer during childhood. Br f Cancer 1987;56:331-8.

17 Hawkins MM, Draper GJ, Kingston JE. Incidence of second primary tumour among childhood cancer survivors. Br f Cancer 1987;56:339-47.

18 Rimm IJ, Li FC, Tarbell NJ, Winston KR, Sallan SE. Brain tumors after cranial irradiation in childhood acute lymphoblastic leukemia. Cancer 1987;59:1506-8

19 Albo V, Miller D, Lekien S, Sather H, Hammond D. Nine brain tumours as a late effect in children "cured" of acute lymphoblastic leukaemia from a late effect in children "cured" or acute lymphot

20 Farwell J, Flannery JT. Cancer in relatives of children with central-nervoussystem neoplasm. N Engl f Med 1984:311:749-54.

21 Soffer D, Pittaluga S, Feiner M, Beller AJ. Intracranial meningiomas following low-dose irradiation to the head. F Neurosurg 1983;59:1048-53.

22 Amendola BE, Amendola MA, McClatchey KD. Radiation-induced malignan fibrous histiocytoma: a report of five cases including two occurring pos whole brain irradiation. Cancer Invest 1985;3:507-13.

23 Tucker MA, Coleman CN, Cox RS, Varghese A, Rosenberg SA. Risk of second cancers after treatment for Hodgkin's disease. $N$ Engl $\mathcal{J}$ Med 1988;318:76-81.

24 Parker RG. Radiation induced cancer as a factor in clinical decision making. Int f Radiat Oncol Biol Phys 1990;18:993-1000.

(Accepled 10 March 1992) 